\title{
Innovative Surgical Technique in the Management of Vallecular Cyst
}

\author{
Munish Saroch ${ }^{1 *}$, Rajnish Sharma ${ }^{2}$ and Amit Saini ${ }^{3}$ \\ ${ }^{1}$ Associate Professor, RPGM College, India \\ ${ }^{2}$ Assistant Professor, SLBS Govt Medical College, India \\ ${ }^{3}$ Senior Resident, ENT \& HNS DRRPGMC, India
}

*Corresponding author: Munish Kumar Saroch, Associate Professor ENT DRRPGMC Kangra, Tanda, HP. India, Email: drsaroch@gmail.com

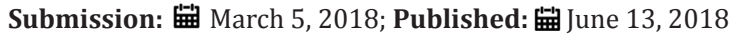

Abstract

A retention cyst arising from the left vallecula in 47 year old man was surgically excised using an Eve's tonsillar snare and there was no recurrence.

\section{Introduction}

Among the benign lesions in the larynx and laryngopharynx, cystic lesions are common entities. Vallecular cysts are usually retention cysts of the minor salivary glands. An innovative method of surgical treatment of one such case is presented here.

\section{Case Report}

A 47 year old man presented with difficulty in swallowing for the last 8 months for solid and liquid foods, h/o change in voice for the last 6 months. Preliminary examination and indirect laryngoscopy revealed $3 \mathrm{~cm} \times 4 \mathrm{~cm}$ swelling in the region of left half of vallecula. Tracheostomy of patient was done and general anesthesia was given through it. Then direct laryngoscopy was done in morning sniffing position which showed the cystic mass arising from the vallecula. Keeping in mind the conventional modalities of treatment like marsupialisation, deroofing etc. we decided to remove vallecular cyst by snaring.

\section{Procedure}

The Boyle- Davis mouth gag, used for exposure of the oropharynx for tonsillectomy, was engaged and cyst was adequately visualized. The Eve's tonsillar snare was engaged around the base of the cyst and with its cutting and crushing action the cyst was removed. Minimal bleeding from the wound was controlled with bipolar cautery. The postoperative period was uneventful and patient was discharged on 6th post-operative day after decannulation was completed and tracheostoma was closed successfully. On review one week later, the wound was found to have healed completely and no recurrence was reported yet (Figure 1-3).

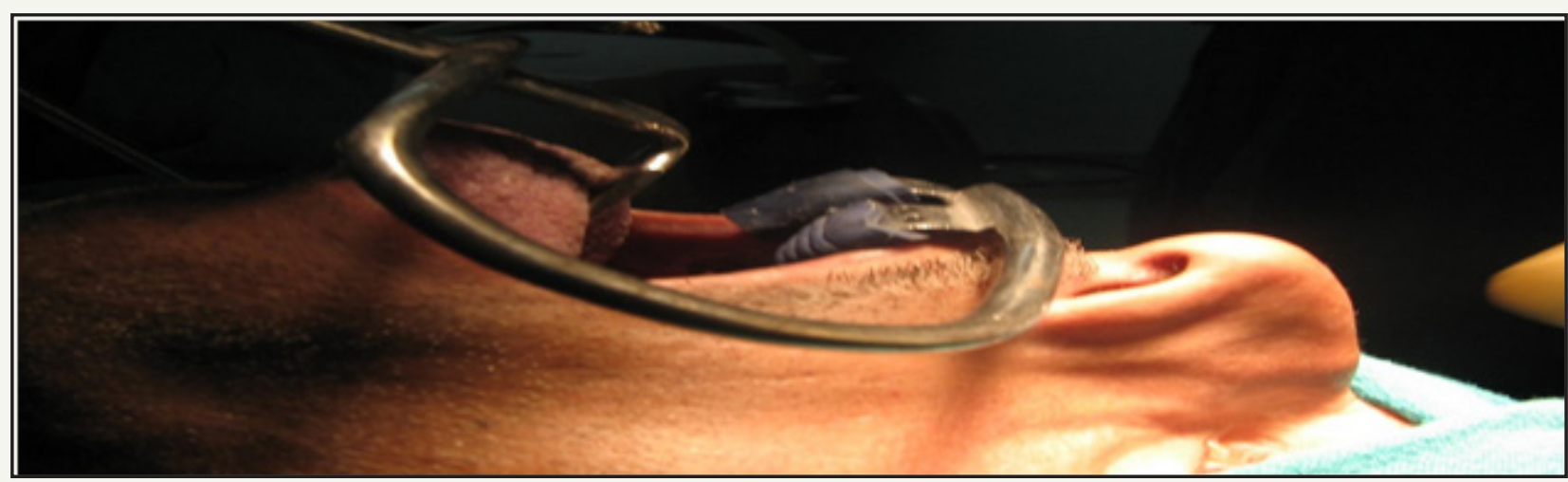

Figure 1: Showing Boyles Davis mouth gag in surgery. 


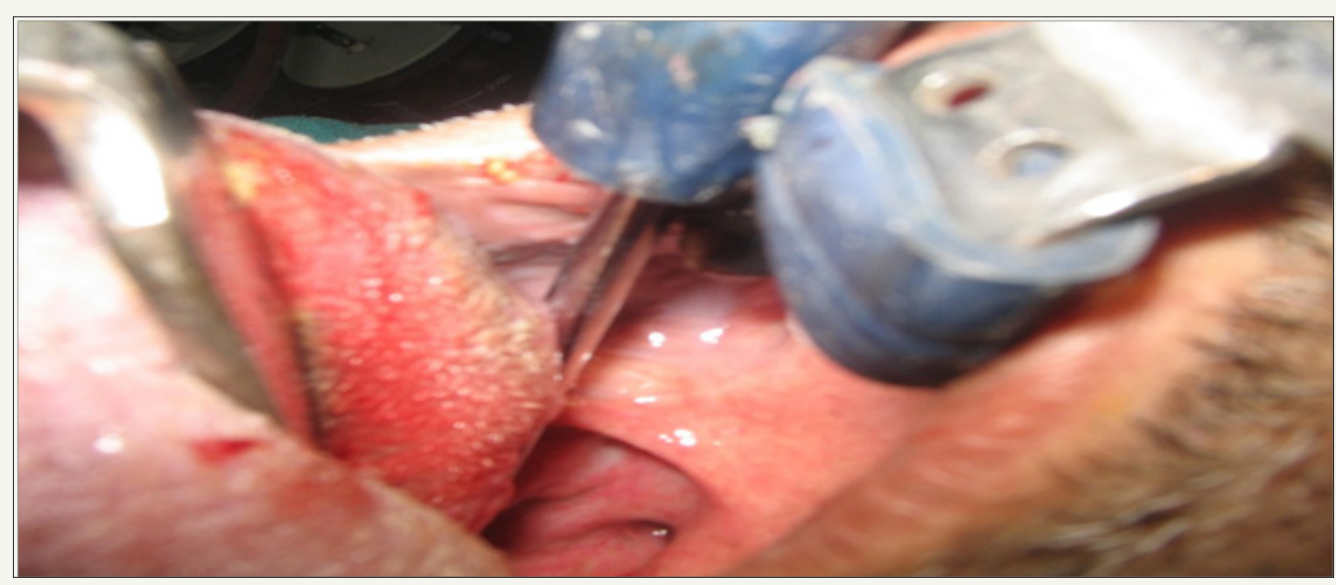

Figure 2: Showing vallecular cyst.

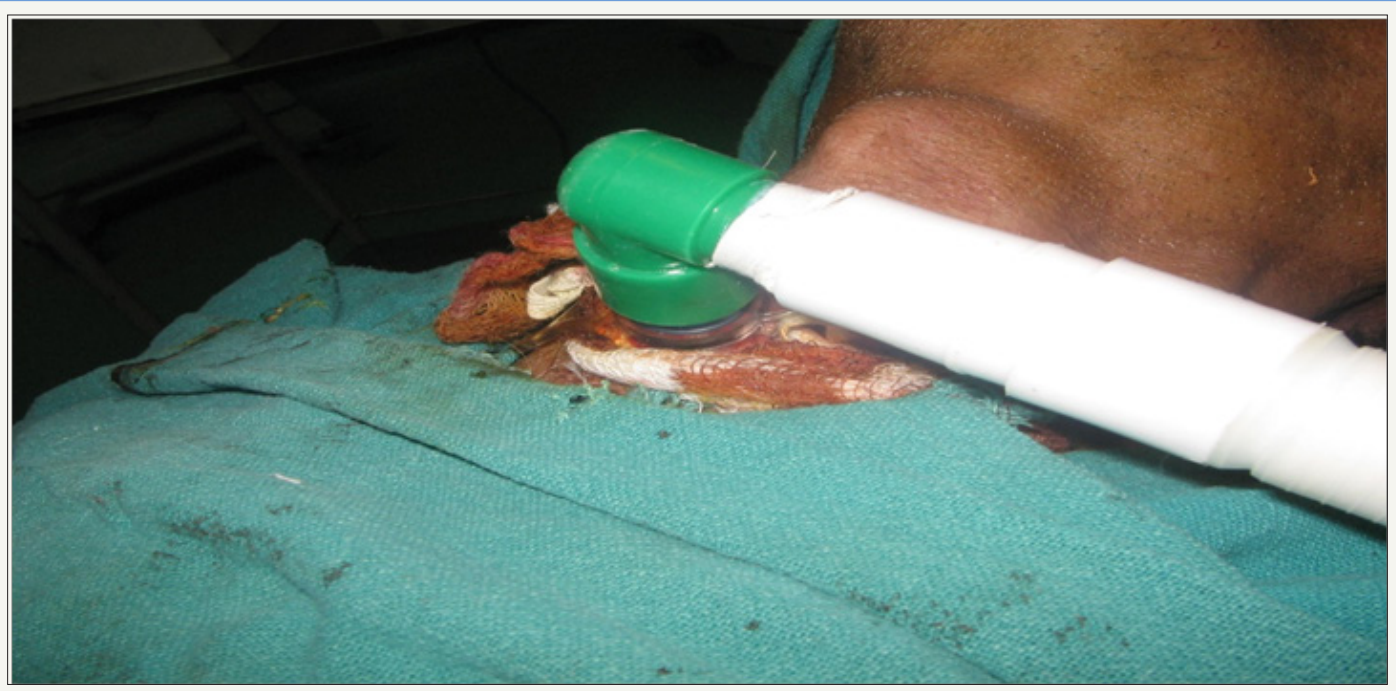

Figure 3: Showing tracheostomy tube in situ just completing surgery.

\section{Discussion}

Vallecular cysts are retention cysts of minor salivary glands in the vallecula and base of tongue. Obstruction of the mucous glands leads to cyst formation and continued secretion leads to corresponding increase in size of the cyst. They are asymptomatic when small in size, but large cysts may cause dysphagia and voice change. Majority of patients presenting with vallecular cysts are in the paediatric age group, most of them being infants [1-4]; in infants and children it may present with upper aero digestive tract obstruction and stridor. Differential diagnoses include

1) Internal thyroglossal cysts

2) Dermoid cysts

3) Lingual thyroid

4) Teratomas

5) Lymphangiomas

\section{Haemangiomas}

The conventional modalities of management of vallecular cyst include

1) Marsupialisation

2) Deroofing

3) Excision

These are either done with CO2 laser or by electrocautery. Repeated aspiration invariavely leads to recurrence of the cysts. The technique adopted by us i.e., snaring of cyst is quick and effective way of surgical removal. This procedure can also be done with set of tonsillectomy instruments. This method is safe, cost effective and results are comparable with that by conventional techniques. Age does not restrict the method of excision and snaring is relatively simple and inexpensive method for the removal of vallecular cysts. Latest method is with microdebrider. 


\section{References}

1. Tuncer U, Aydoğan LB, Soylu L (2002) Vallecular cyst: a cause of failure to thrive in an infant. I nt J Pediatr Otorhinolaryngol 65(2): 133-135.

2. Gutiérrez JP, Berkowitz RG, Robertson CF (1999) Vallecular cysts in newborns and young infants. Pediatr Pulmonol 27(4): 282-285.
3. Ku AS (2000) Vallecular cyst: report of four cases--one with co-existing laryngomalacia. J Laryngol Otol 114(3): 224-226.

4. Robin PE (1997) Tan Olofsson. Tumors of the Larynx. In: Hibber J (Ed.), ( $6^{\text {th }}$ edn), Butterworth-Heinemann, UK, pp. 1-11. (c) (i) Creative Commons Attribution 4.0

For possible submissions Click Here
Submit Article

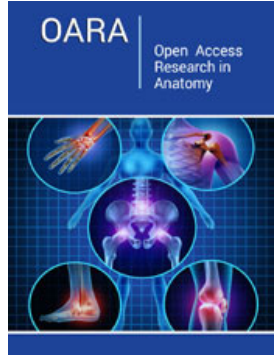

\section{Open Access Research in Anatomy}

Benefits of Publishing with us

- High-level peer review and editorial services

- Freely accessible online immediately upon publication

- Authors retain the copyright to their work

- Licensing it under a Creative Commons license

- Visibility through different online platforms 